Check for updates

Cite this: Mater. Adv., 2022, 3,2146

Received 2nd December 2021, Accepted 10th January 2022

DOI: $10.1039 / \mathrm{d} 1 \mathrm{ma01136g}$

rsc.li/materials-advances

\section{A waste to energy approach for the effective conversion of solid waste plastics into graphene nanosheets using different catalysts for high performance supercapacitors: a comparative study}

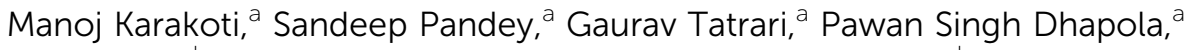 \\ Ritu Jangra, ${ }^{\mathrm{b}}$ Sunil Dhali, ${ }^{\mathrm{a}}$ Mayank Pathak, ${ }^{a}$ Suman Mahendia ${ }^{\mathrm{b}}$ and \\ Nanda Gopal Sahoo (iD *a
}

\begin{abstract}
Presently, plastic waste management is an urgent issue around the globe that is not easy to resolve. We have made an attempt to resolve this issue by synthesizing graphene nanosheets (GNs), which are later exploited for supercapacitor applications. Herein, we report a multidimensional remediation approach for the mass scale production of GNs from plastic waste using zinc oxide ( $\mathrm{ZnO}$ ) and montmorillonite (MMT) clay as the catalysts and templates. Subsequently, supercapacitor (SC) cells are fabricated from the GNs synthesized using $\mathrm{ZnO}$ and MMT, and show good electrochemical performance with specific capacitances of $72.8 \mathrm{~F} \mathrm{~g}^{-1}$ and $377.4 \mathrm{~F} \mathrm{~g}^{-1}$, respectively. In addition, the GNs synthesized using MMT showed the highest energy and power densities of $21.1 \mathrm{~W} \mathrm{~h} \mathrm{~kg}^{-1}$ and $1010.0 \mathrm{~W} \mathrm{~kg}^{-1}$, respectively. Essentially, the use of MMT is able to mainly generate GNs with up to $\sim 2$ layers from waste plastics; these GNs are more regular with less defects, which helps in enhancing the electrochemical performance of the cell. Thus, our study revealed that the choice of catalyst and template in a given GNs manufacturing process can alter the morphology and quality of the GNs, which ultimately affects their electrochemical performance in SC cells. We hope that this study can serve as a crucial breakthrough to deal with global threats such as plastic waste pollution and provide an economical option for the fulfilment of global energy demands.
\end{abstract}

\section{Introduction}

Over the past few years, plastic-based goods have grown as an integral part of human life. This is mainly due to their high thermal stability, low cost, easy processing, light weight, flexibility, chemical inertness, durability, etc. Plastics can be used for many applications, such as packaging, storage, electrical insulation, etc. ${ }^{1}$ However, plastics are also associated with several disadvantages, such as low degradation rates and toxicity, which lead to massive environmental pollution as well as adverse health effects on living organisms. An unusual burst in the population worldwide has caused an astonishing increase in the demand and supply of plastic products, which is increasing the rate of disposal of plastic waste in our surroundings. According to the World Wide

\footnotetext{
${ }^{a}$ Prof. Rajendra Singh Nanoscience and Nanotechnology Centre, Department of Chemistry, DSB Campus, Kumaun University, Nainital 263001, India. E-mail:ngsahoo@yahoo.co.in

${ }^{b}$ Department of Physics, Kurukshetra University, Kurukshetra 136119, India
}

Fund, plastic production has reached approximately 396 million tons and emits 2 billion tons of atmospheric $\mathrm{CO}_{2}$ annually. ${ }^{2}$ This report also indicated that plastic production will increase by up to $40 \%$ by 2030 . The recycling process is regarded as the most suitable technology to resolve the current problem of waste plastics, but it is still poorly developed, resulting in the recycling of only $20 \%$ of total plastic waste. Due to this low recycling rate, the disposal of plastic waste is increasing and has reached an alarming situation. Consequently, appropriate management of plastic waste disposal has become a challenging issue for the scientific community and environmentalists. Therefore, recycling and upcycling methods are well recognized as the most suitable solutions for waste plastic management. These methods are more significant if they can produce value-added products from plastic waste, such as fuels, gases, and additives for concrete material, that have similar or different characteristics to the original plastic products. $^{3-7}$ Usually, plastics are hydrocarbon-based polymers that are made up of carbon, hydrogen and oxygen. Due to the presence of such high carbon content in plastic, it can be used as 
a good and affordable precursor for the synthesis of carbon nanomaterials (CNMs). Recently, several studies of the conversion of different kinds of plastic waste into CNMs such as carbon nanofibers (CNFs), carbon nanotubes (CNTs), carbon spheres (CSs), graphene, etc., have been reported. ${ }^{8-17}$ Among these, graphene is a very fascinating and mysterious material for the present century. It has many excellent properties, including high mechanical and electrical properties, high surface area and uniform pore distribution. Therefore, graphene can be used in various applications, such as fuel cells, biosensors, supercapacitors (SCs), drug delivery materials, polymer nanocomposites, etc. ${ }^{18-22}$ The carbon skeleton of plastic can be a good and inexpensive precursor material for the synthesis of graphene-based materials. In this regard, we have also successfully converted waste plastic through the pyrolysis technique for the bulk synthesis of high quality graphene, as previously reported elsewhere. ${ }^{23}$

Energy storage is another active issue facing the entire scientific research community around the globe. SCs have provided a new impulse and attracted abundant attention due to their capability to fulfil the global energy demand based on their excellent energy storage capacity, high cycling stability and high power density with moderate energy density. SCs are essentially made up of an active material coated on two current collectors that are separated by a suitable electrolyte-soaked separator. ${ }^{24}$ In recent years, a great deal of research has been focused towards the development of suitable active materials for high-performing SCs. Therefore, a number of active materials, including porous activated carbon, different forms of carbon, conducting polymers, metal oxides, etc., have been used in SCs. At present, CNMs, especially graphene, are attracting a great deal of scientific attention as an active material for SC electrodes. ${ }^{25}$

Graphene nanosheets (GNs) synthesized from plastic waste using MMT as the catalyst and template have been reported previously elsewhere, ${ }^{26,27}$ and their utilization as an active material for SC applications on different types of current collectors in gel electrolyte have also been studied. ${ }^{27}$ Here, we report the supercapacitive performance of multilayer and $\sim 2$ layer GNs prepared from waste plastics using either $\mathrm{ZnO}$ or montmorillonite (MMT) via pyrolysis. The cells fabricated from the ZnO-generated GNs (ZGNs) and MMT-generated GNs (MGNs) show specific capacitances of $72.8 \mathrm{~F} \mathrm{~g}^{-1}$ and $377.4 \mathrm{~F} \mathrm{~g}^{-1}$, respectively, in aqueous $1 \mathrm{M} \mathrm{H}_{3} \mathrm{PO}_{4}$ electrolyte.

\section{Experimental part}

\subsection{Materials}

Here, we used waste plastics as a precursor for the synthesis of GNs using ZnO and MMT as degradation catalysts and templates following our previously reported work. ${ }^{23,26,27}$ Other chemicals, such as acetone, nitric acid $\left(\mathrm{HNO}_{3}\right)$, hydrochloric acid ( $\mathrm{HCl})$, phosphoric acid $\left(\mathrm{H}_{3} \mathrm{PO}_{4}\right)$, and polyvinylidene fluoride (PVDF) polymer with a molecular weight of $534000 \mathrm{~g} \mathrm{~mol}^{-1}$ were purchased from Sigma Aldrich and used as received. The graphite sheets used as current collectors were purchased from the Madras Asbestos store.

\subsection{Synthesis of GNs using MMT and ZnO}

The GNs obtained from waste plastics using MMT (MGNs) were synthesized according to our previous work. ${ }^{27}$ Furthermore, the bulk production of GNs using $\mathrm{ZnO}$ as a catalyst and template (ZGNs) was almost the same as that for MMT. Briefly, for this purpose, $35 \mathrm{~kg}$ of plastic waste was chopped into fine pieces using a shredder, followed by washing with a soap solution and distilled water for the removal of unwanted impurities. Subsequently, the chopped plastic was dried in a dryer, and then mixed with the desired amount of $\mathrm{ZnO}(0.5 \mathrm{wt} \%)$ in a mixer unit.

The shredded plastics mixed with $\mathrm{ZnO}$ were placed in a primary pyrolysis chamber for the primary stage pyrolysis at $400{ }^{\circ} \mathrm{C}$ for $2 \mathrm{~h}$ in an inert $\mathrm{N}_{2}$ atmosphere. We obtained a black carbonic charred residue, which was further placed into a secondary pyrolysis unit for high-temperature exfoliation of the carbonic material at $920{ }^{\circ} \mathrm{C}$ for $3 \mathrm{~h}$ in an inert $\mathrm{N}_{2}$ atmosphere (Fig. 1). Subsequently, the obtained black carbonic residue was crushed in a ball mill to make a powder, and then washed sequentially with $5 \% \mathrm{HCl}$, distilled water, ethanol, and distilled water. Finally, the ZGNs were dried overnight in an oven at $80{ }^{\circ} \mathrm{C}$. The yield of MGNs was about $\sim 15 \%$, while that of ZGNs was about $\sim 13 \%$, with the rest forming liquid and gas fuels. The yield of the GNs from plastic waste may be attributed to the effect of the catalyst used for the present study. Accordingly, due to the high carbon content present within the plastic waste, the degradation products of the pyrolysed plastics act as the feedstock for the growth of the GNs. During pyrolysis, the degradation of the waste plastic into light hydrocarbon gases, liquid olefins with short and long chains, and small amounts of aromatics including mono-aromatics, di-aromatics and polycyclic aromatic hydrocarbons occurred; these are again degraded with the effect of temperature. The gaseous degraded products mainly consist of a mixture of light hydrocarbons such as methane, ethane, propane, ethylene, propylene, and isobutene, along with some percentage of hydrogen. ${ }^{28-31}$ These light hydrocarbons, especially methane and aromatics, are the main constituents responsible for the growth of the GNs. To promote the formation of these lightweight hydrocarbons and aromatics during the pyrolysis process, MMT clay acts as a degrading catalytic template, improving the formation of these light hydrocarbons and aromatics. This fact was also confirmed by GC-MS analysis in previous reports in the literature, in which the introduction of MMT clay within the plastic waste matrix enhanced the formation of hydrogen or methane 2- to 2.5-fold, while also enhancing the aromatic content 3 - to 4 -fold. ${ }^{32}$ Hence, by providing assistance for the formation of methane and other aromatics via the slow degradation of the plastics during pyrolysis, MMT clay provides a pathway and sufficient time for nucleation of the graphene skeleton. Therefore, MMT can generate $\sim 2$ layer MGNs. Similarly, the use of transition metals and their oxides has also been reported for the faster production of methane during the catalytic degradation of plastics through the pyrolysis process. $^{33,34}$ Therefore, $\mathrm{ZnO}$ promotes the faster production of methane and also helps in the thermal cracking of the methane for the nucleation of the GNs. However, due to the fast cracking process provided by $\mathrm{ZnO}$, the formation of gaseous and liquid by-products 

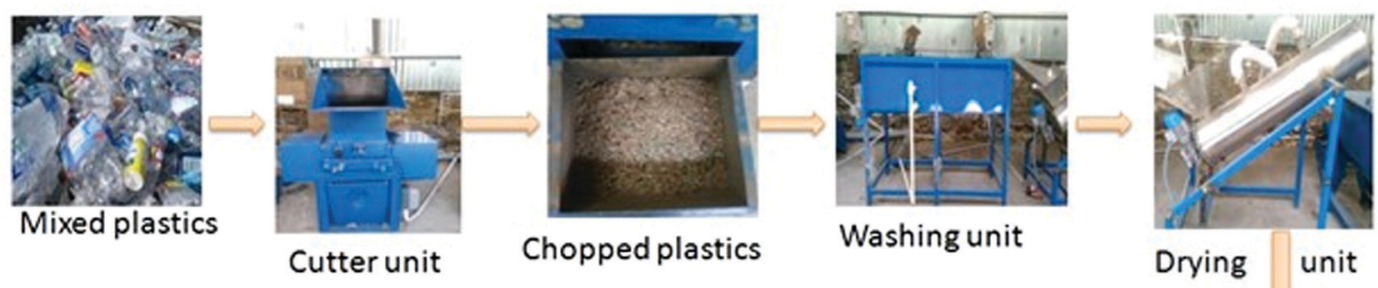

\section{Cutter unit}

Chopped plastics

Washing unit

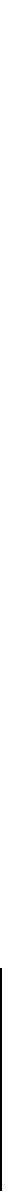
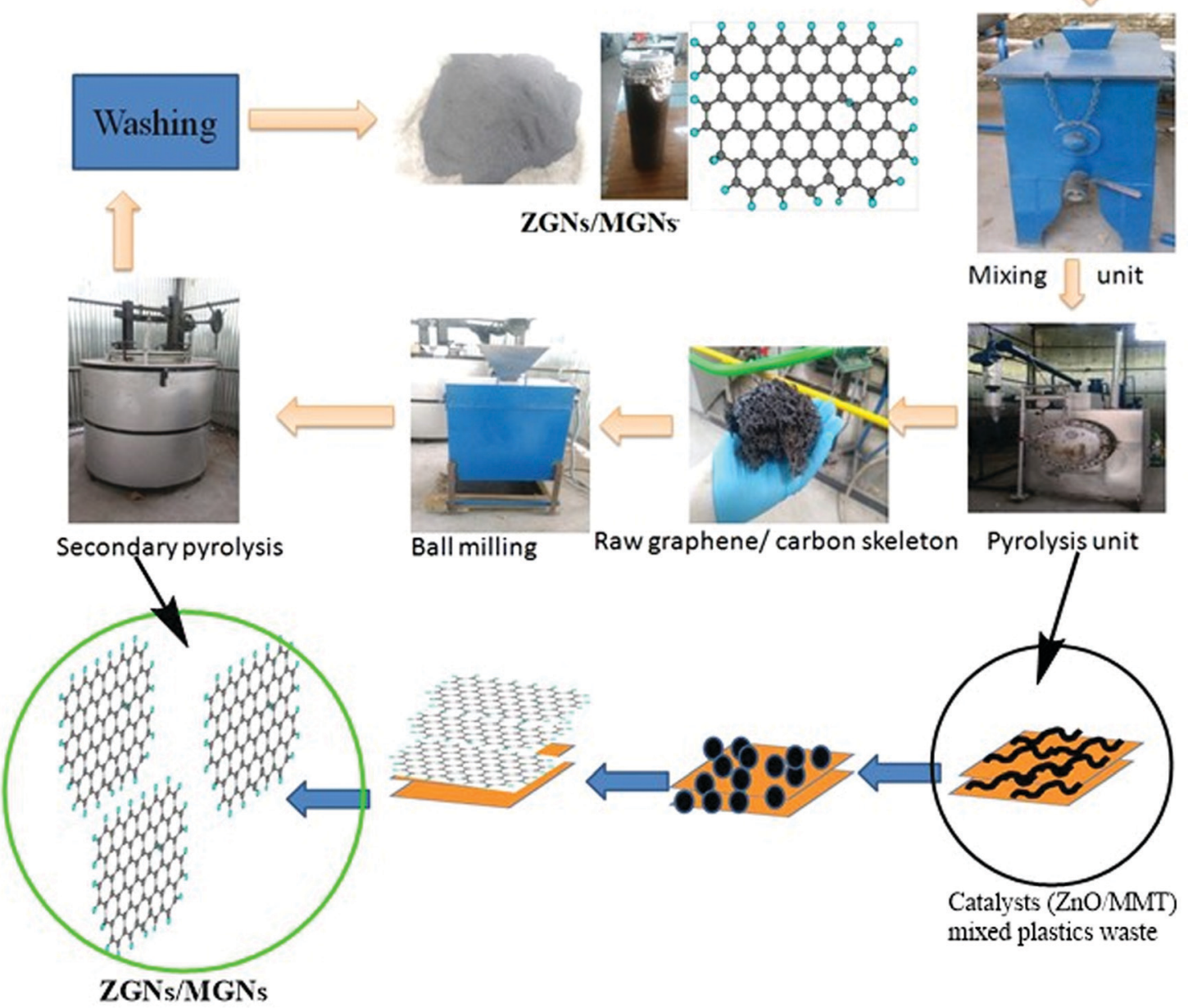

Ball milling

Raw graphene/ carbon skeleton Pyrolysis unit

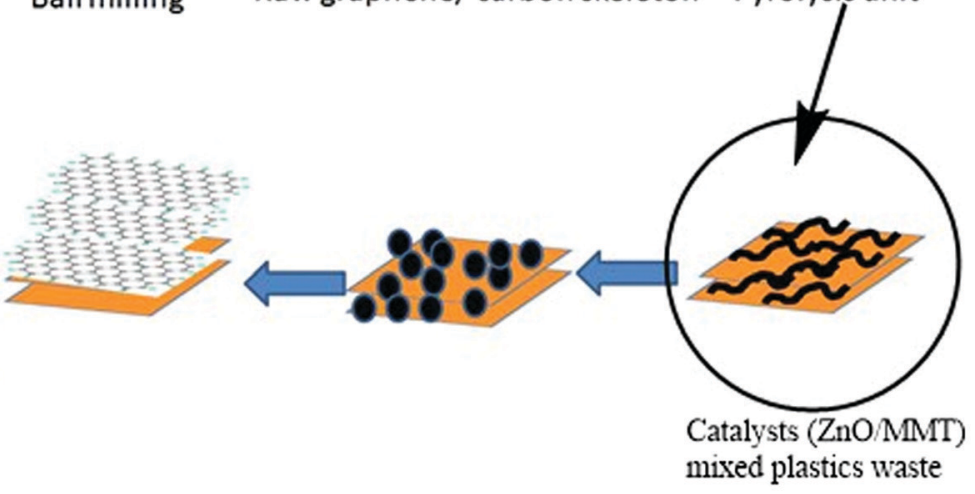

Fig. 1 Process for the synthesis of ZGNs and MGNs from waste plastics.

increases, which in turn affects the yield and quality of the GNs. Therefore, the quality of the ZGNs was also found to be lower than that of the MGNs, and hence, multilayer ZGNs were obtained in the ZnO-catalyzed process.

\subsection{Fabrication of cells}

Cell fabrication was carried out using both the synthesized ZGNs and MGNs in $1 \mathrm{M} \mathrm{H}_{3} \mathrm{PO}_{4}$ electrolyte to fabricate Cell-1 and Cell-2, respectively, as presented in Table 1 and Fig. 2. Initially, we made a sticky paste of ZGNs or MGNs with $10 \mathrm{wt} \%$ of PVDF as a binder (in acetone) via uniform mixing with a mortar and pestle.

The prepared GN paste was coated onto two symmetrical graphite sheets $(1 \mathrm{~cm} \times 1 \mathrm{~cm})$ with a mass loading of $\sim 1 \mathrm{mg}$ on each sheet and dried in an oven for $24 \mathrm{~h}$. Thereafter, the two dried ZGN/MGN-coated electrodes were arranged in such a way
Table 1 Architectures of the fabricated devices

\begin{tabular}{ll}
\hline S. No. & Cell architecture \\
\hline Cell-1 & GS | ZGNs / $1 \mathrm{M} \mathrm{H}_{3} \mathrm{PO}_{4} \mid$ ZGNs | GS \\
Cell-2 & GS $\mid$ MGNs / $1 \mathrm{M} \mathrm{H}_{3} \mathrm{PO}_{4} \mid$ MGNs | GS \\
\hline
\end{tabular}

as to form a sandwich-like structure separated by Millipore filter paper soaked in aqueous $1 \mathrm{M} \mathrm{H}_{3} \mathrm{PO}_{4}$ electrolyte, as presented in Fig. 2 and Table 1.

\section{Characterization}

\subsection{Material characterization}

We performed different characterization techniques for the identification and structural confirmation of the synthesized 


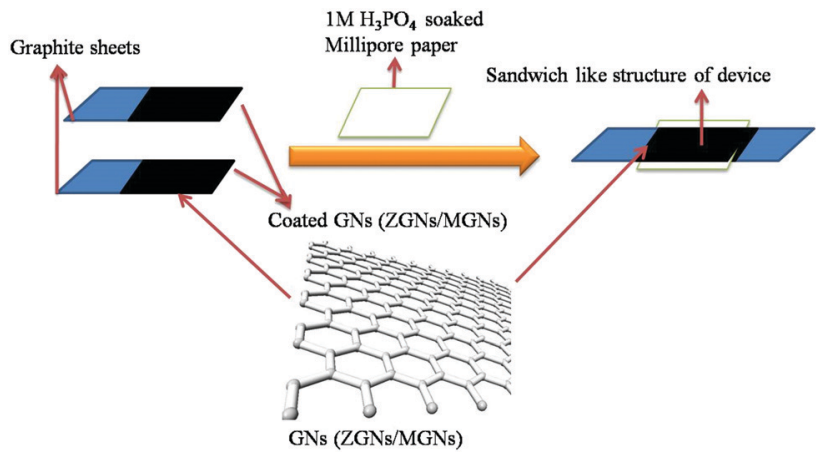

Fig. 2 Flow chart representing the fabrication process of the ZGN- and MGN-based cells.

MGNs. ${ }^{27}$ The characterization of the prepared ZGNs was achieved with the help of the well-known Raman spectroscopy technique to analyze the vibrational properties of the synthesized materials using a HORIBA Japan Xplor Plus with an excitation beam length of $532 \mathrm{~nm}$. To identify their internal and layer structure, the ZGNs were investigated under a JEOL-2100 transmission electron microscope (TEM) that was operated at an acceleration voltage of $200 \mathrm{kV}$. Field emission scanning electron microscope (FESEM) images were taken using a Nova NanoSEM 450 for the surface morphology and elemental analysis of the ZGNs. XRD was also performed for both the ZGNs and MGNs using a Rigaku Miniflex-II with $\mathrm{Cu}-\mathrm{K}($ alpha) radiation of wavelength $k=1.5418 \AA$. Furthermore, the software ImageJ was used for the evaluation of the surface morphologies and internal structure of the ZGNs and MGNs. Atomic force microscopy (AFM) of the GNs and MGNs was carried out using a Bruker Multimide 8 for measurement of their thickness and evaluation of the number of graphene sheets in scanasyst mode.

\subsection{Device characterization}

The electrochemical performances of the fabricated SC cells were evaluated using an Electrochemical Workstation, CHI660E, CH Instruments, Inc. This electrochemical workstation was used to perform the cyclic voltammetry (CV), galvanostatic charge/ discharge (GCD), and electrochemical impedance spectroscopy (EIS) tests, which are the most common and important tests for evaluating the performance of SCs. ${ }^{27,35,36}$

$\mathrm{CV}$ is an important technique for evaluating the capacitance and cyclic behavior of SC cells over the operating voltage range. The cells showed curves with rectangular and nearly rectangular shapes over the operating voltage range of $-1 \mathrm{~V}$ to $1 \mathrm{~V}$ at different scan rates. The specific capacitances of the cells were evaluated from the CV curves using eqn (1) below:

$$
C=\frac{i}{S}
$$

where $i$ is the current and $s$ is the scan rate.

The charge/discharge behaviors of the prepared SC cells were investigated over the potential range of $0 \mathrm{~V}$ to $1 \mathrm{~V}$ at different current densities in the galvanostatic condition.
The specific capacitance was evaluated from the GCD curves using eqn (2) below:

$$
C_{\mathrm{d}}=\frac{i \Delta t}{\Delta V}
$$

where $i$ is the discharge current, $\Delta t$ is the discharge time and $\Delta V$ is the potential window range.

EIS was used for the investigation of the specific capacitance and equivalent series resistance (ESR) of the fabricated SC cells in the frequency range of $10 \mathrm{mHz}$ to $10^{6} \mathrm{~Hz}$, which lies in between $Z^{\prime}$ and $Z^{\prime \prime}$, which are the real and imaginary parts of the impedance of the cells, respectively. The specific capacitance value was evaluated using eqn (3) below:

$$
C_{\mathrm{T}}=-\frac{1}{2 \pi f Z^{\prime \prime}}
$$

where $f$ is the operating frequency and $Z^{\prime \prime}$ is the imaginary part of the impedance.

Furthermore, some other important energy factors, namely, the energy density $\left(\mathrm{W} \mathrm{h} \mathrm{kg}^{-1}\right)$ and power density $\left(\mathrm{W} \mathrm{kg}^{-1}\right)$, were calculated for the fabricated SCs cells using the expressions (4) and (5) below:

$$
\begin{gathered}
\text { Energy density }(E)=\frac{1}{2} C_{\mathrm{d}} \Delta V^{2} \\
\text { Power density }(P)=\frac{E}{t}
\end{gathered}
$$

where $C_{\mathrm{d}}, V$ and $t$ are the specific capacitance from GCD, operating voltage, and discharge time, respectively.

\section{Results and discussion}

\subsection{Structural and morphological characteristics}

Fig. 3(a) shows the Raman spectrum of the ZGNs. This spectrum shows the characteristic peaks of graphene for the ZGNs at $1340 \mathrm{~cm}^{-1}$ and $1589 \mathrm{~cm}^{-1}$, which corresponded to the D and $\mathrm{G}$ bands, respectively. The $\mathrm{D}$ band, also called the deformation band, originates from the defect-induced breathing mode of the $\mathrm{sp}^{2}$ rings due to the presence of some oxygen functional groups. On the other hand, the $\mathrm{G}$ band is attributed to the first-order scattering of the $\mathrm{E}_{2 \mathrm{~g}}$ phonon of the $\mathrm{sp}^{2} \mathrm{C}$ atoms of the ZGNs. Furthermore, the intensity ratio $I_{\mathrm{D}} / I_{\mathrm{G}}$ shows the quality of and the defects present in the ZGNs. The $I_{\mathrm{D}} / I_{\mathrm{G}}$ ratio of the ZGNs was 1.001 , which is higher than that of graphite $(0.403)^{37}$ and graphene oxide, ${ }^{38}$ indicating the generation of new graphitic domains for $\mathrm{sp}^{2}$ clusters with some defects in the ZGN sheets. ${ }^{39}$ This spectrum also exhibited one other peak at $2691 \mathrm{~cm}^{-1}$, which corresponded to the $2 \mathrm{D}$ band. The broad $2 \mathrm{D}$ band originated due to double resonance, and the intensity ratio $I_{2 \mathrm{D}} / I_{\mathrm{G}}$ of 0.97 indicated the presence of multilayer graphene layers in the ZGN sheets. On the other hand, the Raman spectra of reported MGNs showed an intensity ratio $I_{2 \mathrm{D}} / I_{\mathrm{G}}$ of 1.08 , which is greater than that for the ZGNs; higher $I_{2 \mathrm{D}} / I_{\mathrm{G}}$ indicates greater purity and quality for graphene. ${ }^{27,39-43}$

Fig. 3(b) and (c) show the XRD spectra of ZGNs and MGNs, respectively. The XRD spectra exhibited the characteristic border 

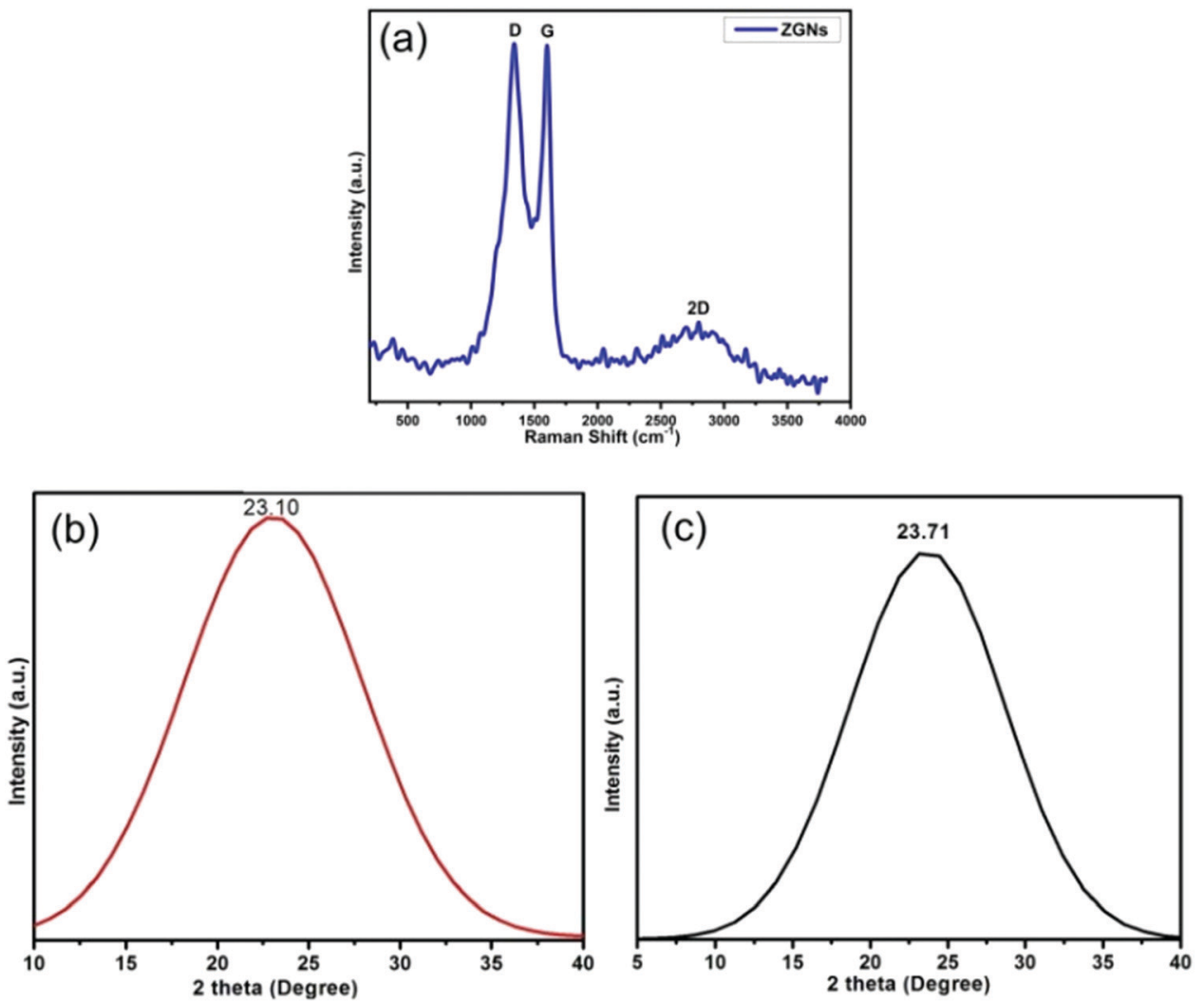

Fig. 3 (a) Raman spectrum of the ZGNs; (b) and (c) XRD spectra of the ZGNs and MGNs, respectively.

peaks of graphene at $2 \theta=23.10^{\circ}$ and $2 \theta=23.71^{\circ}$ for the ZGNs and MGNs, respectively. The interlayer spacing $(d)$ for the ZGNs is $3.99 \AA$, and that of the MGNs is $3.75 \AA$; these were calculated from the Bragg equation ${ }^{44}$ and clearly indicated the formation of GNs.
AFM is generally used for the identification of the thickness and roughness of single-layer to multilayer graphene. Here, the theoretical thickness of $0.69 \mathrm{~nm}$ for two-layer graphene and the $0.335 \mathrm{~nm}$ interlayer spacing of graphite were used as reference
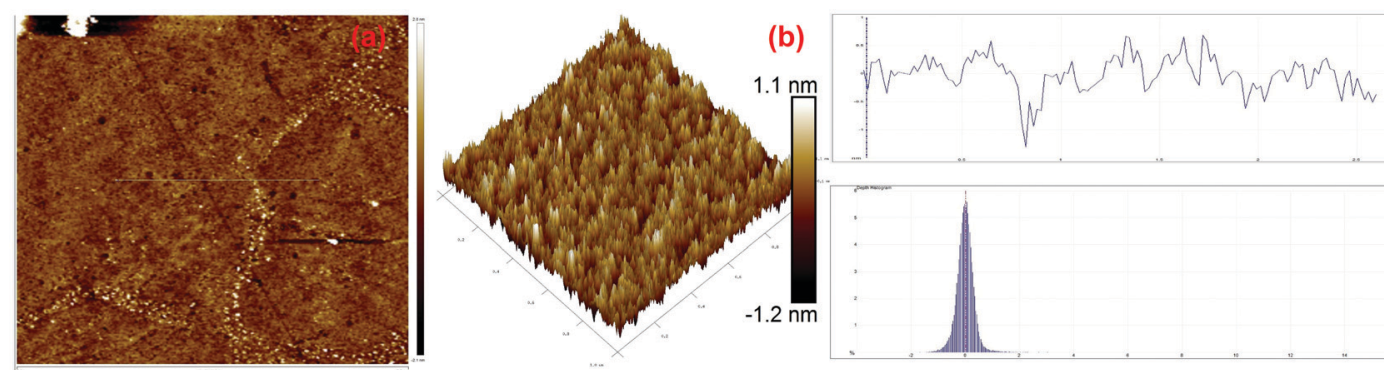

(c)
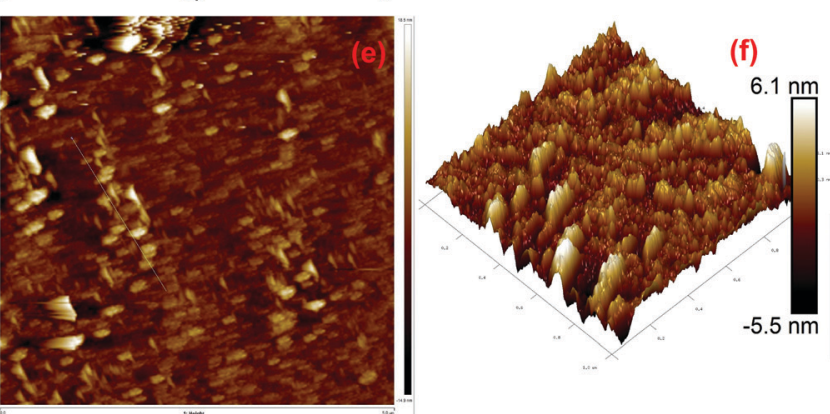

(g)

(d)

(h)

Fig. 4 AFM: (a) and (b) 2D and 3D images of MGNs. (c) Height profile of MGNs. (d) Tri-modal frequency distribution depth histogram of MGNs. (e) and (f) 2D and 3D images of ZGNs. (g) Height profile of ZGNs. (h) Tri-modal frequency distribution depth histogram of ZGNs. 
values to estimate the number of graphene layers. ${ }^{45,46}$ Fig. 4 presents the AFM images, height profiles and tri-modal frequency distribution depth histograms of the MGNs and ZGNs. Fig. 4(a) and (b) show the 2D and 3D AFM surface images of the MGNs, respectively, which indicate the smoothness and uniform pore distribution of the GNs. Fig. 4(c) presents the height profiles from the AFM image of MGNs; the height was about $\sim 0.7 \mathrm{~nm}$, which indicated the formation of $\sim 2$ layers of GNs. ${ }^{46}$ On the other hand, the 2D and 3D AFM (Fig. 4(e) and (f)) surface images of the ZGNs showed a rough and disturbed pore distribution. Fig. 4(g) shows the height profiles of the AFM image of ZGNs; the height was about $\sim 10 \mathrm{~nm}$, which indicates the formation of multilayer GNs. ${ }^{45}$ Additionally, the tri-modal frequency distribution depth histograms (Fig. 4(d) and (h)) of the MGNs and ZGNs exhibited good resemblance with the height profiles of their AFM images. The AFM results showed good agreement with the Raman and TEM analysis. It is well known that the surface properties and number of layers of GNs greatly affect the performance of SCs. Single-layer to few-layer graphene provides low-resistance pathways and short ion diffusion channels that enhance the performance of SCs. ${ }^{4-49}$ Therefore, the MGN-based SC cell showed higher supercapacitive performance than the ZGN-based SC cell.

Fig. 5(a) and (b) present the 3D surface plot and plot profile from the previously reported TEM images of MGNs for comparison. $^{27}$ These images show the presence of 2-3 layers within the MGNs. The 3D surface morphology of the MGNs clearly showed corrugated edges with reduced grain boundaries; because of these features, the MGNs showed good capacitive behavior for supercapacitor applications. ${ }^{50}$ As the capacitive behavior of carbon-based materials also depends on the surface roughness and number of defects present within the carbonaceous material, surface roughness analysis was also carried out.

Fig. 5(c) and (d) exhibit the Hill stack view and 3D surface topology from the previously reported SEM images of the $\mathrm{MGNs}^{27}$ and are used here for comparison only. The 3D surface topology and Hill stack view from the SEM image of the MGNS shows the presence of uneven hills of graphene layers with curly edges and sharp spikes within the MGNs, which enhanced the defect densities within the MGN layers and hence developed a metallic nature within the MGNs, as reported in our previous studies. ${ }^{23,34,50}$

Fig. 6(a)-(d) present the FESEM images of the ZGNs. Fig. 6(a) shows the clear and distinctive surface morphology of the ZGNs at a magnification scale of $1 \mu \mathrm{m}$. This image exhibits various lines, which are interconnected stacks of graphene layers; this indicates the multilayer structure of the ZGNs. Fig. 6(b) and (d) present the side view of the ZGNs, and clearly show some poroustype structures, which may be helpful for the insertion of electrolyte ions, which is greatly responsible for the capacitance behavior of the ZGN-based cells. Fig. 6(c) demonstrates the surface morphology of the ZGNs at a magnification of $500 \mathrm{~nm}$. Stacks of ZGNs with side edge defects, grain boundaries, and random clusters of graphene layers with wrinkles at the surfaces can be seen on the surface of the ZGNs.

Fig. 7(a) shows the FESEM image of the ZGNs taken for the evaluation of the Hill stack plot and surface morphology using the software ImageJ. Fig. 7(b) and (c) present the Hill stack plot and 3D surface morphology of the FESEM images of the ZGNs. The Hill stack plot and 3D surface morphology clearly show (a)

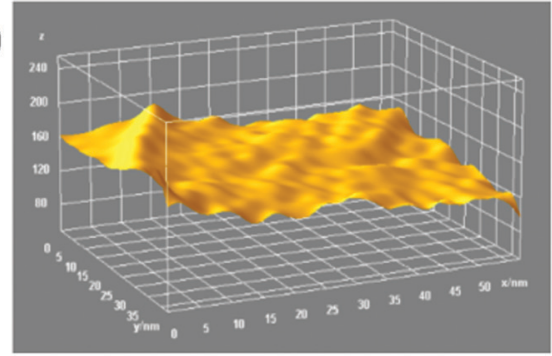

(c)

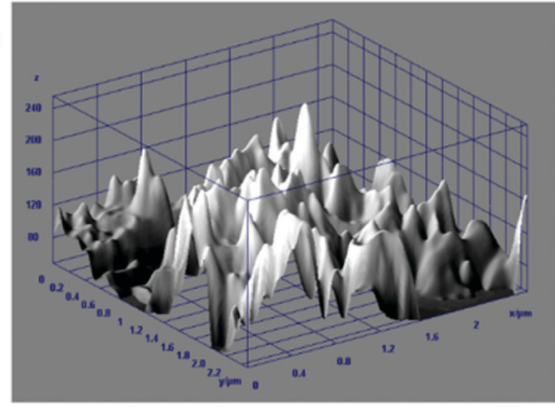

(b)

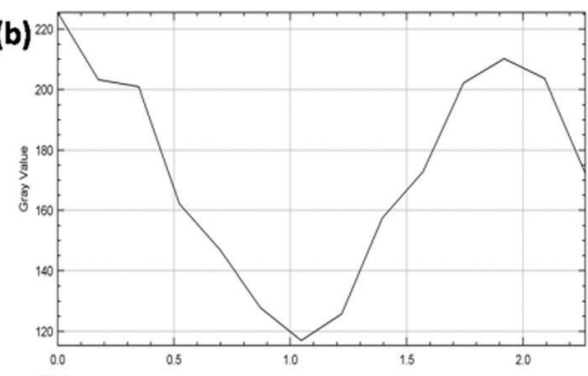

(d)

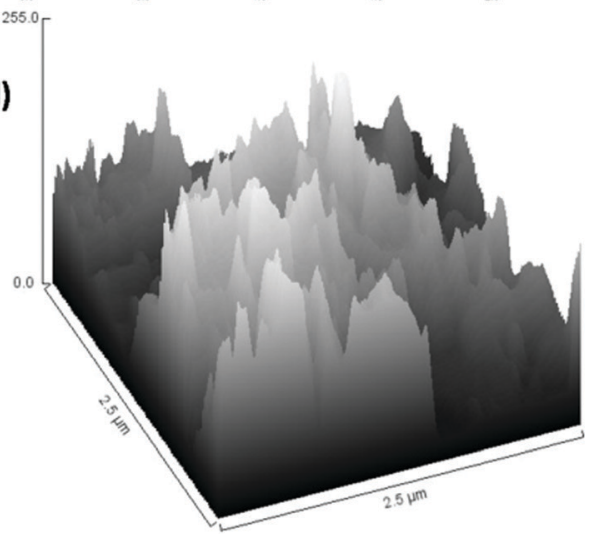

Fig. 5 (a) 3D surface plot from TEM analysis of MGNs. (b) Plot profile diagram from the thickness measurement of MGNs. (c) 3D surface topology from the SEM analysis of MGNs. (d) Hill stack plot of MGNs showing surface roughness. 


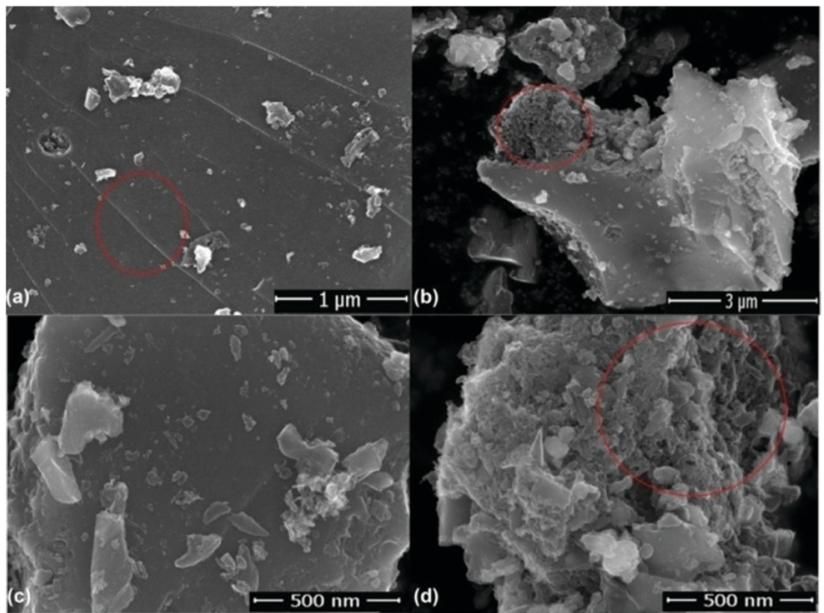

Fig. 6 FESEM images of ZGNs (a)-(d).

lower surface roughness and defect densities compared to that of the MGNs, because of which greater crystalline behavior was found for the ZGNs than for the MGNs. Hence, the MGNs should exhibit higher capacitive behavior than the ZGNs. In order to prove this, we fabricated SC cells based on the MGNs and ZGNs as the active materials, and the results for the cells showed good agreement with this concept.

Fig. 8 presents the TEM images of ZGNs, which were obtained to investigate the internal morphology and structure of the ZGNs. Fig. 8(a) presents the TEM image of the ZGNs at a magnification of $5 \mathrm{~nm}$, which clearly depicts the presence of multilayer ZGNs with the presence of the edge defects. Furthermore, the ZGNs also exhibited grain boundaries with a crumpled

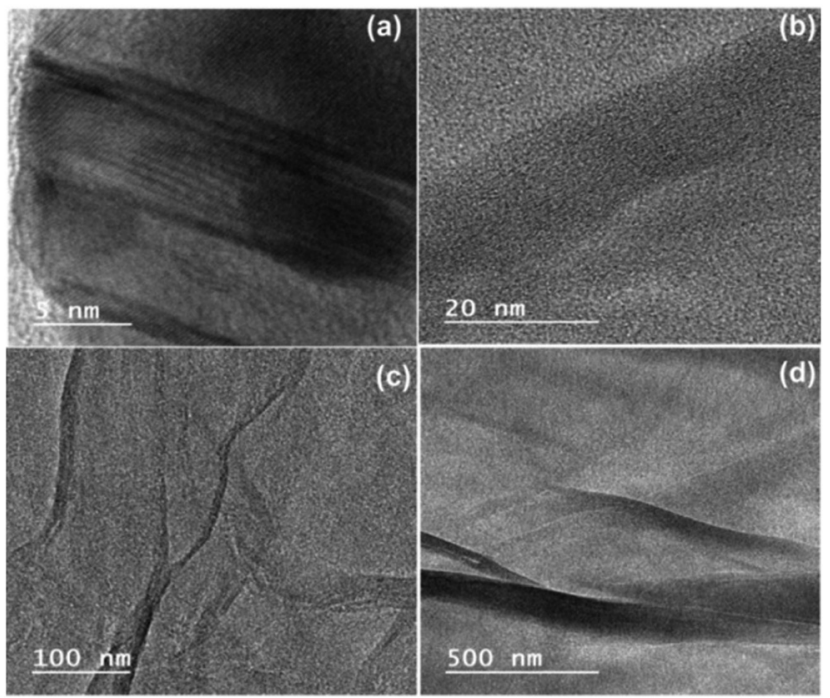

Fig. 8 TEM images of ZGNs (a)-(d).

morphology, as depicted in Fig. 8(b). The presence of curved and crumpled morphology can be clearly visualized in Fig. 8(c), in which the layers of the ZGNs are visualized at a magnification of $100 \mathrm{~nm}$. The crumpled morphology of the ZGNs showed a smoother surface, and the layer stacks of the ZGNs could also be visualized, as shown in Fig. 8(d). Because of the multilayer morphology of the ZGNs, the capacitive property of the ZGNs resulted in average performance in the SC cell.

Fig. 9(a) and (b) present the TEM images of the ZGNs at magnifications of $100 \mathrm{~nm}$ and $500 \mathrm{~nm}$, which were taken for the evaluation of the 3D surface morphology and plot profile (a)

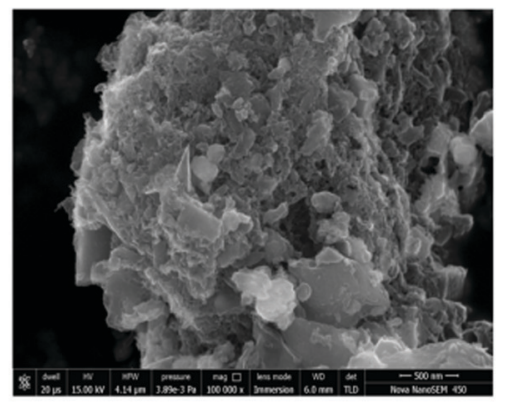

(b)

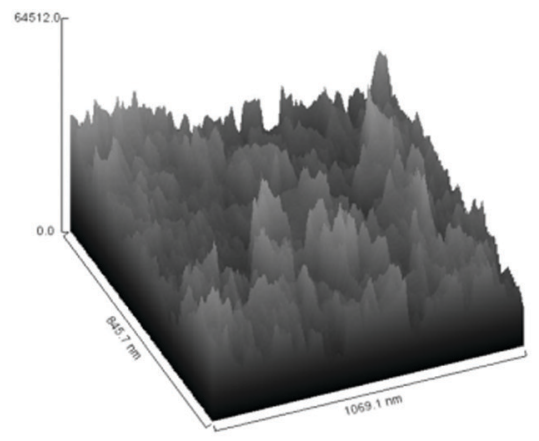

(c)

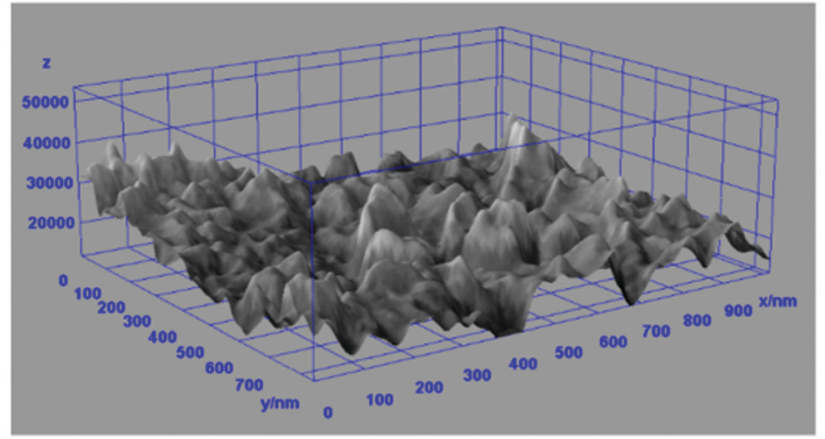

Fig. 7 (a) FESEM image of ZGNs. (b) Hill stack plot of the ZGNs a500 nm. (c) 3D surface morphology from the FESEM images. 
(a)

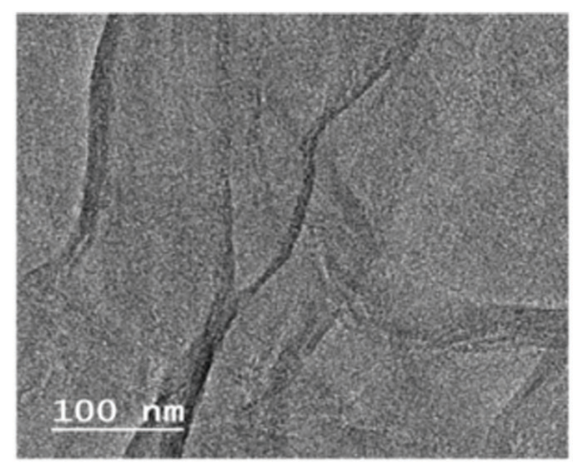

(c)

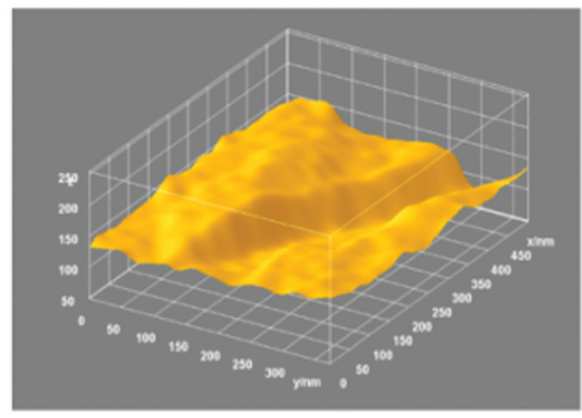

(b)

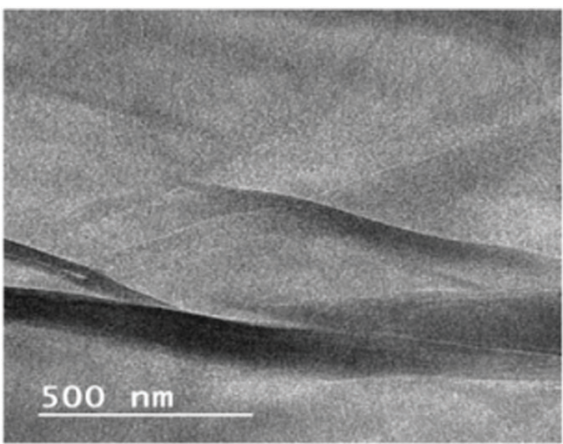

(d)

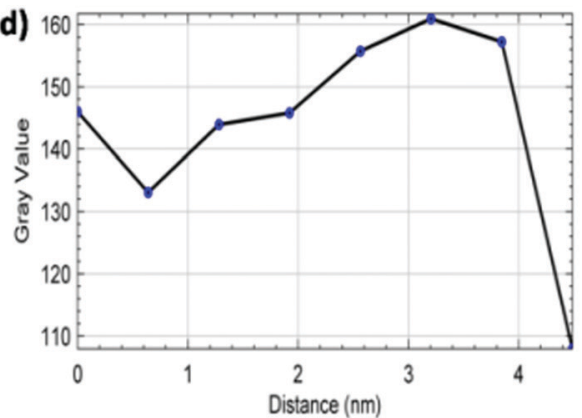

Fig. 9 (a) TEM image of ZGNs a100 nm resolution. (b) TEM image of ZGNs a500 nm. (c) 3D surface morphology from the TEM images. (d) Plot profile diagram showing the average number sheets present within the ZGNs.

diagram. The TEM images of the ZGNs also showed corrugated edges, like those shown by the MGNs; however, the grain boundaries were found to be higher in the ZGNs than in the MGNs. Fig. 9(c) provides a clear view of the grain boundaries present within the ZGNs. Furthermore, the ZGNs also showed the presence of multiple layers in the GNs, and the number of layers was found to be higher than that in the MGNs. ${ }^{27}$

Further, EDX was also performed for the quantitative analysis of the elements present in the ZGNs; the results are exhibited in the map sum spectrum in Fig. 10. The EDX spectra showed that the ZGNs were composed of carbon, which was present in hexagonal form, and oxygen, which was present in the form of oxidative groups in the ZGNs. In addition, Table 2 shows the percentages of carbon (84.97 wt\%) and oxygen (15.03 wt\%) present in the ZGNs.

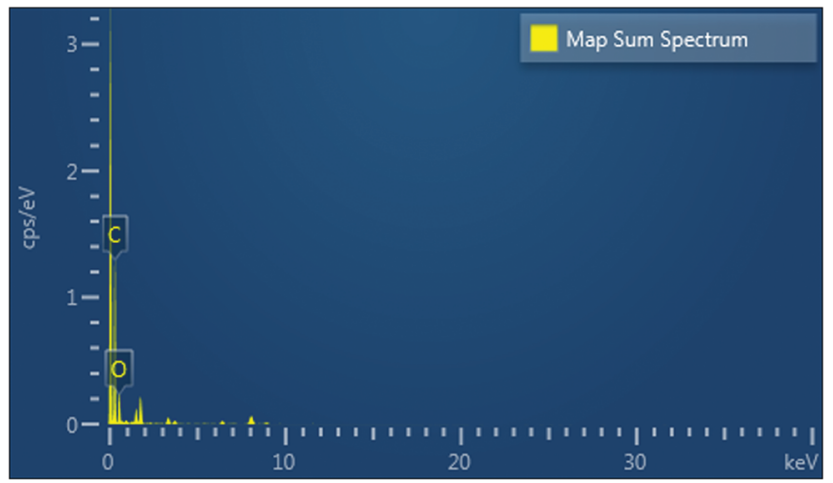

Fig. 10 Map sum spectrum of ZGNs obtained via EDX.
Table 2 Elemental analysis of ZGNs via EDX

\begin{tabular}{llrl}
\hline Element & Absorption correction & Wt\% & Wt\% sigma \\
\hline $\mathrm{C}$ & 1.00 & 84.97 & 0.82 \\
$\mathrm{O}$ & 1.00 & 15.03 & 0.82 \\
Total & & 100.00 &
\end{tabular}

\subsection{Device performance}

The electrochemical performances of the SC cells fabricated using the ZGNs and MGNs (Cell-1 \& Cell-2) are listed in Table 1. CV plots of the fabricated Cell 1 and Cell 2 were recorded in the voltage range of $-1 \mathrm{~V}$ to $+1 \mathrm{~V}$ at different scan rates $\left(5 \mathrm{mV} \mathrm{s}^{-1}\right.$, $10 \mathrm{mV} \mathrm{s}^{-1}, 50 \mathrm{mV} \mathrm{s}^{-1}, 100 \mathrm{mV} \mathrm{s}^{-1}$, and $200 \mathrm{mV} \mathrm{s}^{-1}$ ), as shown in Fig. 11(a) and (b).

The CV curves of Cell- 1 show an almost-rectangular shape and nearly mirror-image symmetry in terms of the current response about the zero current line at all scan rates. This clearly indicated the capacitive behavior of Cell-1, which also exhibited the formation of a double layer at the electrodeelectrolyte interface. Cell-2 exhibits nearly rectangular-shaped curves at lower scan rates and quasi-rectangular CV curves at higher scan rates. The CVs of both show typical EDLC-type behavior with high rate capability and low internal resistance over the tested voltage range. ${ }^{51}$ Furthermore, the specific capacitances for Cell-1 and Cell-2 were calculated using eqn (1) and found to be $72.8 \mathrm{~F} \mathrm{~g}^{-1}$ and $377.4 \mathrm{~F} \mathrm{~g}^{-1}$, respectively, at the lowest current rate, i.e., $5 \mathrm{mV} \mathrm{s}^{-1}$. At a high scan rate of $200 \mathrm{mV} \mathrm{s}^{-1}$, we found gradual loss of specific capacitance for both cells (Table 3 ) because the delayed penetration of ions 

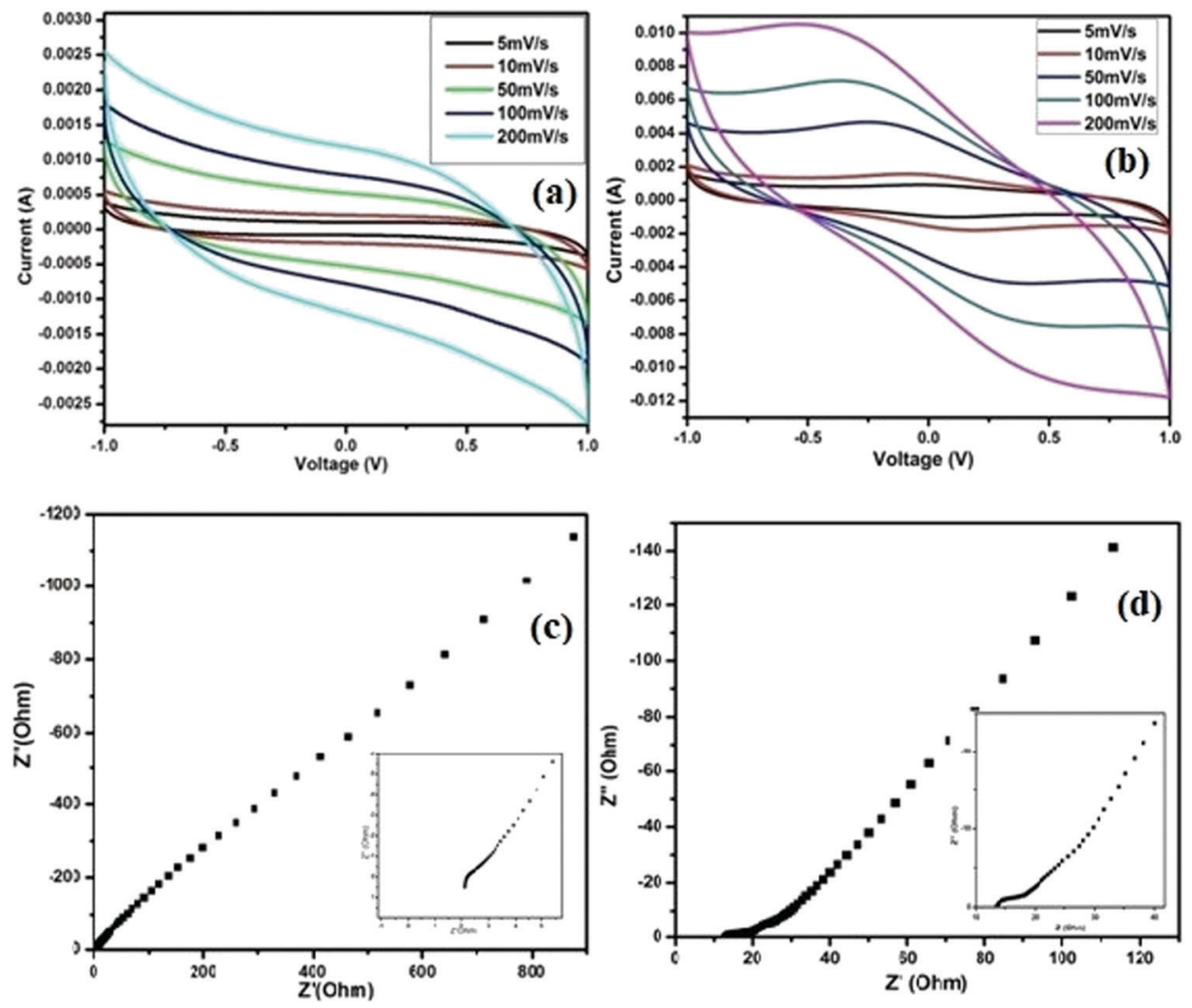

Fig. 11 CV analyses and EIS spectra of Cell-1 and Cell-2. (a) CV of the ZGN-based cell, (b) CV of the MGN-based cell, (c) EIS of the ZGN-based cell, and (d) EIS of the MGN-based cell in aqueous $1 \mathrm{M} \mathrm{H}_{3} \mathrm{PO}_{4}$ electrolyte.

inside the pores produces lower charge and lower capacitance values.

Nyquist plots of EIS spectra are a universally used technique for identifying the frequency-dependent behavior and supercapacitive characteristics of fabricated cells. The impedance spectra of fabricated cells were recorded over a frequency range of $10 \mathrm{mHz}$ to $10^{6} \mathrm{~Hz}$ and are shown in Fig. 11(c) and (d), respectively, for Cell-1 and Cell-2. The impedance responses of the cells show a sharp rising action and are parallel to the imaginary impedance axis for both cells in the low-frequency region up to $10 \mathrm{mHz}$. In these spectra, Cell-2 shows a sharper rising action parallel to the imaginary impedance axis. Also, the behavior of both cells in the lower-frequency region indicated the formation of a double layer at the interface of the electrode and electrolyte. In addition, both spectra showed bulk resistance in the higher-frequency range or left side of the spectra due to the electrolytes and the contact resistance that evolved between the graphite sheets and ZGNs/MGNs. As a result, the ESR for Cell-1 is $2.1 \mathrm{Ohm} \mathrm{cm}^{-2}$, and that of Cell-2 was $13.5 \mathrm{Ohm} \mathrm{cm}^{-2}$, which indicated faster charging and discharging in Cell-1 as compared to Cell-2. Furthermore, the specific capacitance value calculated for Cell-2 was $224.4 \mathrm{~F} \mathrm{~g}^{-1}$, compared to $28.4 \mathrm{~F} \mathrm{~g}^{-1}$ for Cell-1 (Table 4); these values were evaluated using eqn (2).

Fig. 12(a) and (b) present the GCD curves of the ZGN-/MGNbased cells, i.e., Cell-1 and Cell-2. The figures show the discharge phenomena characteristics of the SCs at each operating
Table 3 Specific capacitances $\left(C_{s}\right)$ values of Cell-1 and Cell-2 at different scan rates

\begin{tabular}{lcccll}
\hline & \multicolumn{3}{c}{$C_{\mathrm{s}}\left(\mathrm{F} \mathrm{g}^{-1}\right)$} & & \\
\cline { 2 - 6 } Cell & $5 \mathrm{mV} \mathrm{s}^{-1}$ & $10 \mathrm{mV} \mathrm{s}^{-1}$ & $50 \mathrm{mV} \mathrm{s}^{-1}$ & $100 \mathrm{mV} \mathrm{s}^{-1}$ & $200 \mathrm{mV} \mathrm{s}^{-1}$ \\
\hline Cell-1 & 72.8 & 40.9 & 21.1 & 15.9 & 12.1 \\
Cell-2 & 377.4 & 314.0 & 148.2 & 98.9 & 62.7
\end{tabular}

current density. Both cells show nearly triangular-type curves, which is the basic feature of EDLC-type behavior. Furthermore, the specific capacitance values calculated from the GCD, i.e., the charge-discharge curve, using eqn (3) are $11.2 \mathrm{~F} \mathrm{~g}^{-1}$ and $152.0 \mathrm{~F} \mathrm{~g}^{-1}$ at a current density of $1 \mathrm{~A} \mathrm{~g}^{-1}$ for Cell-1 and Cell-2, respectively. In addition, the specific capacitances for both cells at the higher current densities are shown in Table 4. The specific capacitance of the MGNs on a graphite sheet as a current collector in polymer gel electrolyte (PGE) was determined to be

Table 4 Specific capacitance $\left(C_{\mathrm{s}}\right)$ values of the fabricated cells evaluated using EIS at $10 \mathrm{mHz}$ and GCD at $1 \mathrm{~A} \mathrm{~g}^{-1}$

\begin{tabular}{|c|c|c|}
\hline & $\underline{\mathrm{C}_{\mathrm{s}}\left(\mathrm{F} \mathrm{g}^{-1}\right)}$ & $\mathrm{C}_{\mathrm{s}}\left(\mathrm{F} \mathrm{g}^{-1}\right)$ \\
\hline Cells & EIS & GCD at $1 \mathrm{~A} / \mathrm{g}$ \\
\hline Cell-1 & 28.44 & 11.25 \\
\hline Cell-2 & 224.46 & 152.04 \\
\hline
\end{tabular}



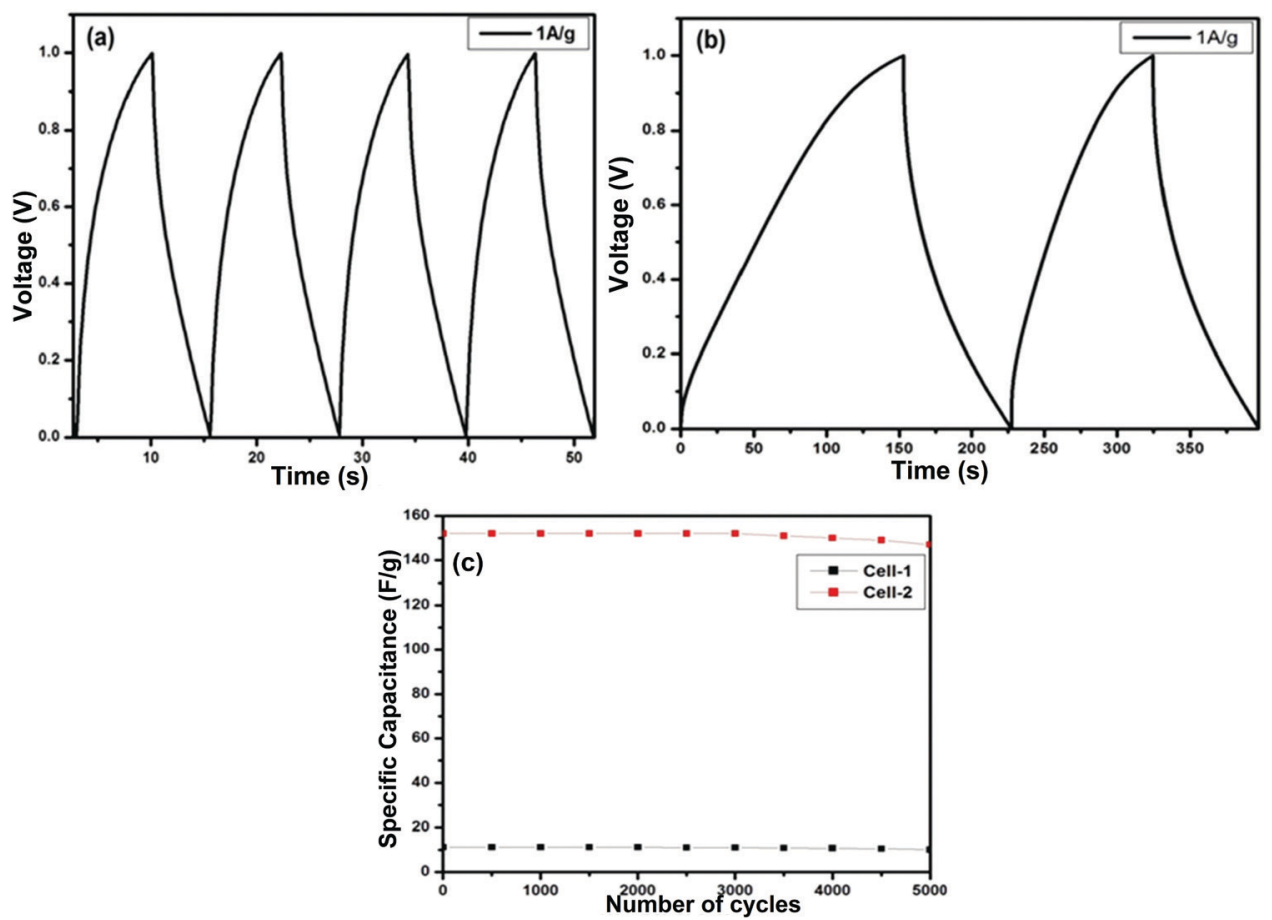

Fig. 12 GCD curves of Cell-1 and Cell-2: (a) ZGN-based cell and (b) MGN-based cell. (C) Charge-discharge over 5000 cycles for Cell-1 and Cell-2 at a current density of $1 \mathrm{~A} \mathrm{~g}^{-1}$ in aqueous $1 \mathrm{M} \mathrm{H}_{3} \mathrm{PO}_{4}$ electrolyte.

$7.8 \mathrm{~F} \mathrm{~g}^{-1}, 10.5 \mathrm{~F} \mathrm{~g}^{-1}$, and $2.8 \mathrm{~F} \mathrm{~g}^{-1}$ using CV, EIS and GCD, respectively, in our previous work. ${ }^{27}$ These values are relatively very small compared with those of Cell 1 and Cell 2 prepared in the present study. This effect was shown by the previously reported cells because of the PGE. Generally, PGE shows lower conductivity and low ion transport because the ions are immobilized in the polymer matrix, which restricts their mobility. Therefore, the ions are not easily accessible at the electrode surface; this fact is responsible for the lower specific capacitance of the cell. In the present case, we have used aqueous electrolyte, which generally shows higher conductivity and faster ion transport compared to PGE; therefore, the electrolyte ions are accessible to the electrode surface, which is directly responsible for the higher specific capacitance. ${ }^{35,52}$

Furthermore, the energy and power density were also calculated for the fabricated cells using eqn (4) and (5), respectively, and are shown in Table 5. It is clearly seen from this table that the use of different catalysts and templates in the synthesis of the GNs derived from waste plastic plays a significant role in enhancing their energy storage application, with energy densities of $\sim 1.6 \mathrm{~W} \mathrm{~h} \mathrm{~kg}^{-1}$ using

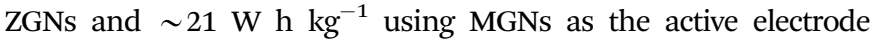
material; both materials provided almost the same power density of $\sim 1010 \mathrm{~W} \mathrm{~kg}^{-1}$.

Table 5 Energy and power density of Cell-1 and Cell-2

\begin{tabular}{lrr}
\hline Characteristic & \multicolumn{1}{c}{ Cell-1 } & \multicolumn{1}{c}{ Cell-2 } \\
\hline Energy density $\left(E_{\mathrm{d}}\right)\left(\mathrm{W} \mathrm{h} \mathrm{kg}^{-1}\right)$ & 1.5 & 21.1 \\
Power density $\left(P_{\mathrm{d}}\right)\left(\mathrm{W} \mathrm{kg}^{-1}\right)$ & 1009.5 & 1010.0
\end{tabular}

Furthermore, cyclic stability is another important factor for the practical application of SCs. To determine the stability of both cells, we performed sequential GCD measurements for 5000 cycles at a current density of $1 \mathrm{~A} \mathrm{~g}^{-1}$ for Cell-1 and Cell-2 (Fig. 12(c)). The cyclic stability results show $89 \%$ retention of the specific capacitance for Cell-1 after 5000 charge- discharge cycles. On the other hand, Cell-2 retained $96 \%$ of its initial capacitance after 5000 charge-discharge cycles.

\section{Conclusion}

As shown by our results, we are targeting a booster step to resolve the environmental and energy storage problems simultaneously. Plastic waste is a serious concern associated with the modern lifestyle due to the extensive use of plastic materials in daily life. Plastic waste creates very serious problems for the environment by occupying large volumes of land, bodies of water, etc. This work will open a new channel for the management of waste plastic and its conversion to useful value-added products and their future applications. Here, we successfully converted waste plastic into multilayer ZGNs and 1-2 layer MGNs and showed their potential towards supercapacitor applications. Our study showed the superiority of MMT over ZnO as a catalyst for the conversion of waste plastic into GNs because of the more pure and appropriate surface morphologies of the resulting GNs. Thus, we can conclude that MMT-based GNs show higher electrochemical behavior performance compared to the ZnO-based GNs because of the good quality of the GNs and their better surface morphology. The synthesized ZGN- and MGN-based cells exhibited excellent 
specific capacitances of $72.88 \mathrm{~F} \mathrm{~g}^{-1}$ and $377.4 \mathrm{~F} \mathrm{~g}^{-1}$ in aqueous $1 \mathrm{M} \mathrm{H}_{3} \mathrm{PO}_{4}$ electrolyte, respectively. Thus, the present study showed that the up-cycling of plastic waste into GNs using low-cost catalytic templates can be used for the conservation of sustainable energy, with both economic and ecological benefits.

\section{Conflicts of interest}

The authors are declaring that there is no conflict of interests.

\section{Acknowledgements}

The authors are highly thankful to the National Mission on Himalayan Studies (NMHS), Almora, India [Ref No.-GBPNI/ NMHS-2019-20/MG] and DST-INSPIRE (Ref. No. - IF180347) for their financial assistance. The authors from Kurukshetra University are thankful to the DST-SERB [Ref No. EMEQ-824/ 2014], New Delhi.

\section{References}

1 J. Parra, C. Ania, A. Arenillas, F. Rubiera, J. Palacios and J. Pis, Bol. Soc. Esp. Ceram., 2004, 43, 547-549.

2 P. Pirotto, WWF Report 2019 on plastic waste pollution: critical issues and action plan, https://www.geoplastglobal. com/en/insights/wwf-report-2019-on-plastic-waste-

pollution-critical-issues-and-action-plan/, accessed 27 May 2019, 2019.

3 L. Ahmad, Plastic Recycling, http://www.lotfi.net/recycle/ plastic.html.

4 P. S. Kumar, M. Bharathikumar, C. Prabhakaran, S. Vijayan and K. Ramakrishnan, Int. J. Energy Environ. Eng., 2017, 8, 167-173.

5 S. Budsaereechai, A. J. Hunt and Y. Ngernyen, RSC Adv., 2019, 9, 5844-5857.

6 Z. Z. Ismail and E. A. Al-Hashmi, Waste Manage., 2008, 28, 2041-2047.

7 J. Kwabena, V. Berko-Boateng and T. Ama, Case Study Constr. Mater., 2017, 6, 1-7.

8 C. Wu, Z. Wang, L. Wang, P. T. Williams and J. Huang, RSC Adv., 2012, 2, 4045-4047.

9 C. Wu, M. A. Nahil, N. Miskolczi, J. Huang and P. T. Williams and technology, J. Environ. Sci., 2014, 48, 819-826.

10 J. Gong, B. Michalkiewicz, X. Chen, E. Mijowska, J. Liu, Z. Jiang, X. Wen and T. Tang, ACS Sustainable Chem. Eng., 2014, 2, 2837-2844.

11 C. Zhuo, B. Hall, H. Richter and Y. Levendis, Carbon, 2010, 48, 4024-4034.

12 J. O. Alves, C. Zhuo, Y. A. Levendis and J. A. Tenório, J. Appl. Catal., B: Environmental, 2011, 106, 433-444.

13 J. C. Acomb, C. Wu and P. T. Williams, Appl. Catal., B, 2016, 180, 497-510.
14 J. Gong, J. Liu, Z. Jiang, X. Wen, X. Chen, E. Mijowska, Y. Wang and T. Tang, Chem. Eng. J., 2013, 225, 798-808.

15 J. Gong, J. Liu, X. Wen, Z. Jiang, X. Chen, E. Mijowska and T. Tang, Ind. Eng. Chem. Res., 2014, 53, 4173-4181.

16 Z. Jiang, R. Song, W. Bi, J. Lu and T. Tang, Carbon, 2007, 45, 449-458.

17 R. Song, B. Li, S. Zhao and L. Li, J. Appl. Polym. Sci., 2009, 112, 3423-3428.

18 J. T. Choi, T. D. Dao, K. M. Oh, H.-I. Lee, H. M. Jeong and B. K. Kim, Smart Mater. Struct., 2012, 21, 075017.

19 V. D. Punetha, S. Rana, H. J. Yoo, A. Chaurasia, J. T. McLeskey Jr, M. S. Ramasamy, N. G. Sahoo and J. W. Cho, Prog. Polym. Sci., 2017, 67, 1-47.

20 C. Liu, Z. Yu, D. Neff, A. Zhamu and B. Z. Jang, Nano Lett., 2010, 10, 4863-4868.

21 H.-J. Choi, S.-M. Jung, J.-M. Seo, D. W. Chang, L. Dai and J.-B. Baek, Nano Energy, 2012, 1, 534-551.

22 S. Afsahi, M. B. Lerner, J. M. Goldstein, J. Lee, X. Tang, D. A. Bagarozzi Jr, D. Pan, L. Locascio, A. Walker, F. Barron and B. R. Goldsmith, Biosens. Bioelectron., 2018, 100, 85-88.

23 S. Pandey, M. Karakoti, S. Dhali, N. Karki, B. SanthiBhushan, C. Tewari, S. Rana, A. Srivastava, A. B. Melkani and N. G. Sahoo, Waste Manage., 2019, 88, 48-55.

24 F. Maher, S. Veronica, D. Sergey and B. Richard, Science, 2012, 335, 1326-1330.

25 Z. Peng, J. Lin, R. Ye, E. Samuel and J. Tour, ACS Appl. Mater. Interfaces, 2015, 7, 3414-3419.

26 N. G. Sahoo, Sandeep, M. Karakoti and V. D. Punetha, India Pat., 352780, 2016.

27 M. Karakoti, S. Pandey, R. Jangra, P. S. Dhapola, P. K. Singh, S. Mahendia, A. Abbas and N. G. Sahoo, Mater. Manuf. Processes, 2021, 36, 171-177.

28 Y. S. Kim, J. H. Lee, Y. D. Kim, S. K. Jerng, K. Joo, E. Kim, J. Jung, E. Yoon, Y. D. Park, S. Seo and S. Chun, Nanoscale, 2013, 5, 1221-1226.

29 X. F. Zhang, J. Ning, X. L. Li, B. Wang, L. Hao, M. H. Liang, M. H. Jin and L. J. Zhi, Nanoscale, 2013, 5, 8363-8366.

30 J. Gong, J. Liu, Z. W. Jiang, X. Wen, X. C. Chen, E. Mijowska, Y. H. Wang and T. Tang, Chem. Eng. J., 2013, 225, 798-808.

31 J. Gong, J. Liu, D. Wan, X. C. Chen, X. Wen, E. Mijowska, Z. W. Jiang, Y. H. Wang and T. Tang, Appl. Catal., A, 2012, 449, 112-120.

32 G. Jiang, J. Liu, X. Wen, Z. Jiang, X. Chen, E. Mijowska and T. Tang, Ind. Eng. Chem. Res., 2014, 53, 4173-4181.

33 J. I. Villacampa, C. Royo, E. Romeo, J. A. Montoya, P. Del Angel and A. Monzon, Appl. Catal., A, 2003, 252(2), 363-383.

34 S. Pandey, A. Kumar, M. Karakoti, K. K. Garg, A. Rana, G. Tatrari, B. S. Bohra, P. K. Yadav, R. K. Singh and N. G. Sahoo, Nanoscale Adv., 2021, 3, 4726-4738.

35 M. Karakoti, R. Jangra, S. Pandey, P. S. Dhapola, S. Dhali, S. Mahendia, P. K. Singh and N. G. Sahoo, High Perform. Polym., 2020, 32, 175-182.

36 G. Pandey and A. Rastogi, MRS Online Proceedings Library, 2012, 1440, 25-30.

37 L. Kou, H. He and C. Gao, Nano-Micro Lett., 2010, 2, 177-183. 
38 F. W. Low, C. W. Lai and S. B. Abd Hamid, Ceram. Int., 2015, 41, 5798-5806.

39 D.-G. Thomas, E. Kavak, N. Hashemi, R. Montazami and N. N. Hashemi, J. Carbon Res., 2018, 4, 42.

40 R. P. Antony, L. Preethi, B. Gupta, T. Mathews, S. Dash and A. Tyagi, Mater. Res. Bull., 2015, 70, 60-67.

41 F. T. Johra, J.-W. Lee and W.-G. Jung, J. Ind. Eng. Chem., 2014, 20, 2883-2887.

42 Z. Tu, Z. Liu, Y. Li, F. Yang, L. Zhang, Z. Zhao, C. Xu, S. Wu, H. Liu and H. Yang, Carbon, 2014, 73, 252-258.

43 C. Lou, S. Wang, T. Liang, C. Pang, L. Huang, M. Run and X. Liu, Mater. Res. Soc. Symp. Proc., 2017, 10, 1068.

44 J. Aladekomo and R. Bragg, Carbon, 1990, 28, 897-906.
45 Z. Lin, P. Karthik, M. Hada, T. Nishikawa and Y. Hayashi, Nanomaterials, 2017, 7(6), 125.

46 Z. Shen, J. Li, M. Yi, X. Zhang and S. Ma, Nanotechnology, 2011, 22(36), 365306.

47 T. Purkait, G. Singh and M. Singh, Sci. Rep., 2017, 7, 15239. 48 M. J. Allen, V. C. Tung and R. B. Kaner, Chem. Rev., 2010, 110, 132-145. 49 Y. Gogotsi, Nature, 2014, 509, 568-570.

50 S. Pandey, M. Karakoti, K. Surana, P. S. Dhapola, B. SanthiBhushan, S. Ganguly, P. K. Singh, A. Abbas, A. Srivastava and N. G. Sahoo, Sci. Rep., 2021, 11, 1-17.

51 Y. Zhou, P. Jin, Y. Zhou and Y. Zhu, Sci. Rep., 2018, 8, 1-7. 52 B. Pal, S. Yang, S. Ramesh, V. Thangadurai and R. J. N. A. Jose, Nanoscale Adv., 2019, 1, 3807-3835. 